\title{
Health and Economic Burdens of Physical Inactivity: Implication for Healthy Lifestyle Promotion
}

\author{
Dr. Omaka-Amari Lois Nnenna ${ }^{1}$, Dr. Irivbemi, Ben-Suru ${ }^{2}$, Dr Emeka U. Mong ${ }^{3}$ \\ Department of Human Kinetics and Health Education Ebonyi State University Abakaliki
}

\begin{abstract}
Physical inactivity is increasingly becoming a global health challenge with lots of implications for individual, family and community health. This paper focused on the Health and Economic Burdens of Physical inactivity and its Implication for Healthy Lifestyle Promotion. The topic was discussed under 4 major headings namely concept description, health and economic burdens of inactivity, and implication for healthy lifestyle promotion. Regarding concept description inactivity was conceived as a state of not moving the body enough to meet the guideline of World Health Organization (WHO) for physical activity. Physical activity on the hand was defined as any movement of the body that causes the muscles to work and demand more energy than that is needed for rest. The major health burdens of physical inactivity as identified in the paper were, increased risk for death, cardiovascular diseases (CVD), bone diseases, cancer and obesity. The paper observed that the economic burden of inactivity arises from the high financial expenditure usually incurred in treating diseases associated with inactivity. It was also revealed that most non-communicable diseases (NCDs) associated with inactivity often results in hospitalization and incapacitation and thus promotes lack of productivity; lose of income and financial dependency. Sequel to the sever burdens of inactivity; the paper identified physical activity as an important lifestyle which is needed to reduce the burdens of inactivity in the world. Places where physical activity could be promoted as discussed in the paper were schools, homes, workplace and community. Physical education, media campaigns, provision of enabling environment and government policies were some of the strategies that were identified as needed for effective promotion of physical activity among the general population. It was therefore recommended among others that health educators should focus on awareness programmes for the promotion of physical activity
\end{abstract}

Keywords: Physical activity, inactivity, health burden, economic burden, promotion

\section{Introduction}

Inactivity in recent times is increasingly becoming a serious health menace with lots of challenging health implications for both the young and old. This is based on the report of IMin, Shiroma, Lebelo, Puska, Biar and Katzmarlyk (2012) that a good proportion of the world's population is not physically active. A 2010 physical activity report stated that up to 81 percent of school children 11-17 years and adults 18 years and above in the world was significantly not involved in moderate to vigorous intensity exercise according to WHO guideline(WHO, 2015). In Nigeria it was reported that $80 \%$ of professionals residing in the urban did not measure up with the WHO recommendations of physical activity (Akarolo-Anthony, \& Adebamowo 2014). These statistical evidences make physical inactivity a global health concern. Being inactive is among the ten leading predisposing risk factors of many diseases such as cardiovascular and bone diseases, obesity, some kind of cancer and diabetes among others (WHO, 2015). Physical inactivity has also been identified as the number four leading risk factor associated with death among the world's population accounting for up to 3.2 million mortalities per year (WHO, 2013).

Physical inactivity is simply a concept used to describe the inability of an individual to obtain the acceptable level of regular physical activity. It is an activity level which is considered lower than WHO recommended guidelines on physical activity for health (O'Riodan, 2012). Inactivity or sedentary living apart from its health consequences has lots of financial implications for individuals, communities and government (Zhang \& Chaaban, 2012). It exerts serious financial burden on health care system of any country and the world at large (Li, 2014). It is not in doubt that the cost of embarking on a tailored programme of physical activity will definitely be far cheaper than that required for the treatment and management of any of the diseases associated with inactivity. More so, the burden of spending valuable time for regular hospital visits and hospitalizations can be averted if individuals engage in meaningful physical activity especially as recommended by WHO. To be physically fit is profitable and it is a prerequisite for healthy living. Unfortunately, due to better technology and consequently improved standard of living individuals do things more conveniently without moving the body much. Besides in the world today work activities both at home and offices are carried out electronically, at times behind a table assuming a seated position that would last for hours. This implies that people are simply not moving their body as much as is required to maintain good health confirming the report of WHO which observed that more than 60 percent of the world's population is significantly inactive. This condition is made worse by the increased tendency towards the consumption of cheap and unhealthy food resulting in increased incidence of obesity and other related health issues (Cleere, 2015; World Heart Federation, 2015).

This state of affair is not interesting and suggests the need for the promotion of healthy lifestyle. A Physically active life is an important lifestyle that should be promoted among individuals in the society. Being physically fit and active has lots of benefits among which include longevity and protection from most deadly health problems. Living a Physically active life is essential in maintaining high quality 


\section{International Journal of Science and Research (IJSR) \\ ISSN (Online): 2319-7064 \\ Index Copernicus Value (2013): 6.14 | Impact Factor (2014): 5.611}

of life as well as improved life expectancy. It is a significant contributing factor necessary for the promotion of overall good health of an individual. Physical fitness which is a product of a physically active life is associated with better mental and musculoskeletal health and reduced risk for most cardiovascular, bone, cancer and nutrition related diseases (Astralian Institute for Health Welfare 2015). People need to be aware of the dangers of inactivity, benefits of an active lifestyle and should be encouraged to engage in physical activities in order to enjoy life and live long. These established importance of physical activity to human lives underscore the appropriateness of the present paper which addressed the burdens of physical inactivity and its implication for the promotion of healthy lifestyle.

\section{Conceptual Description}

\section{Physical Inactivity and Activity}

Physical inactivity simply means sedentary, dormant, and sluggish or being out of use. It is a state of not doing things that demands body movement and energy (Merriam Webster Dictionary, 2015). For this paper inactivity simply means not moving the body enough to meet the WHO guideline for physical activity. There are two categories of inactivity. The first group is inadequate physical activity which involves less than 150 minutes of physical activity per week. The second refers to a total of inactivity which is less than 30minutes per week (New Zealand Ministry of health, 2015). Physical activity on the other hand as conceived by WHO (2015) is any movement of the body originating from the muscles and results in the giving off of energy. National Heart, Lung and Blood Institute (2011) similarly described physical activity as any movement of the body that causes the muscles to work and demand more energy than that is needed for rest. The term has also been generally used to describe any movement that requires the use of energy (NHS Health Scotland, 2015). The American Heart Association (2015) opined that physical activity is any act of an individual that results in the burning of body calories. In a more professional way Bumgardner (2015) defined Physical inactivity as giving out less than $1.5 \mathrm{kcal} / \mathrm{kg} / \mathrm{day}$ in leisure physical activities. This measurement according to the author is equal to a trek that is little more than two kilometers or 1.3 miles or almost 300 steps. This could also be a walk of 25 minutes or less. Baumgartner (2015) while referring to the American Heart Association recommendation stated that in order to remain active and healthy a moderate intensity exercise for 30 minutes per day for five days in a week or a total of 2 hours and 30 minutes a week is needed.

\section{Types of physical activities}

Physical activities embrace a wide category of actions ranging from house chores and gardening to sporting and other outdoor activities (NHS Health Scotland, 2015). There are basically four main types of physical activity these include aerobic, muscle-strengthening, bone-strengthening and stretching activities. Aerobic activities are endurance activities and are useful in maintaining a healthy lung and heart, building stamina and helps in reducing body fat as well as improving circulation. Such activities also help increase heart and breathing rate for an extended period of time thus promoting cardiovascular function while reducing blood pressure. Examples of aerobic activities are walking, stair climbing, swimming, running, cycling, dancing, and jumping. Other aerobic activities include gardening, hiking, Tennis, soccer, hockey, and basketball (National Heart Lung and blood Institution, 2011, Dairy Council of California, 2015). Muscle-strengthening activity includes activities that permit the use of body weight for resistance, such as pushups, pull ups, sit ups and squats. It also includes activities that encourage working with resistance and building of weight. This category of physical activity focuses on improving the strength of the bone and major muscles of the body namely muscles of the legs, hips, back, chest and shoulders (Health Promotion Board, 2012). Bone strengthening activities are running, rope, lifting walking, and jumping. These activities as the name implies are usefully in maintaining strong and healthy bones. Finally, Stretching activities are those that enhance flexibility as well as the ability to move the body joints easily. Examples of this group include toes touching exercise, side stretches, and yoga exercises (National Heart Lung and blood Institution, 2011).

\section{Burdens of Physical Inactivity}

\section{Health burdens}

Being inactive as stated earlier is an important risk factor for all cause of mortality and many health problems. Inactivity is a high grade risk-related lifestyle for every individual whether old or young. Statistical evidence indicated that 9.4 percent of deaths due to any cause are linked to physical inactivity (O'Riodan, 2012). Inactive lifestyle could result to lose of lives (especially in the early years of existence) and reduced life expectancy (Li, 2012; I-Min, Shiroma, Lobelo, Puska, Bliar, and Katzmarlyk, (2012). Individuals who are not sufficiently involved in physical activity are known to possess 20 to 30 percent higher risk of all cause of death compared to physically active individuals (WHO, 2015). Major health problems most frequently associated with inactivity are non-communicable diseases such as cardiovascular diseases, diabetes, colon cancer and breast cancer (I-Min, Shiroma, Lobelo Puska, Bliar, and Katzmarlyk, 2012). Lack of sufficient physical activity offers twice the risk of heart diseases, obesity, and type 2diabetes. Physical inactivity also presents higher risk of developing breast cancer, colon cancer, osteoporosis, lipid disorders, depression and anxiety (South Australian Health 2012).

A 2012 report suggested that a life of inactivity has the same destructive effect as cigarette smoking. It was therefore estimated that physical inactivity was responsible for more than 5.3 million mortalities which was almost equal to the 5million deaths associated with the smoking of cigarette (Cole, 2012, WHO, 2013). Physical in activity was the prime cause of 30 percent of ischaemic heart disease, 27 percent of diabetes, 21 to 25 percent of breast and colon cancers and 13 percent of high blood pressures (WHO, 2015, WHO, 2015). Physical in activity has a part to play in the development of gallstone disease. Gallstone is a disease that indicates the accumulation of hard bile deposits in the gallbladder. Inactivity increases the length of time waste passes through the colon and together with high levels of triglycerides increases the possibility of a gallstone disease

\section{Volume 4 Issue 12, December 2015}




\section{International Journal of Science and Research (IJSR) \\ ISSN (Online): 2319-7064 \\ Index Copernicus Value (2013): 6.14 | Impact Factor (2014): 5.611}

(Depietro, 2011). Another important health consequence of inactivity is being overweight or obese. Individuals who are insufficiently active have very high risk of acquiring excess weight. Over weight and obesity were the greatest health risk observed in a 12 year study which was carried out among 300,000 individuals in Europe. Obesity is particularly a dangerous health condition because the risk of dying early is two times higher among obese individual (Gallagher, 2015). Poor physical activity enhances the loss of muscle tissues thus posing difficulty in the performance of daily tasks and activities. This factor also hinders the maintenance of good body weight (NCHPAD, 2015). Other grievous health consequences frequently associated with inactivity include, dementia, low body immunity, osteoarthritis, and stroke (Depietro, 2011; Health- Manatū Hauora, 2014; NCHPAD, 2015; Li, 2014).

\section{Economic burdens}

Despite the numerous physical and psychological health challenges of physical inactivity, financial burden is another important negative outcome of this health risk. Physical inactivity as earlier stated is an important risk factor of most non-communicable diseases (NCD) such as cardiovascular diseases, diabetes, obesity, bone diseases and cancer among others. These diseases are major cause of adult mortality and morbidity in the world. Due to their characteristic long lasting duration and very slow progression (WHO, 2005) they most often require medical care that runs throughout life thus incurring high and regular financial expenditure. Diseases associated with inactivity are largely chronic in nature, demands regular visits to a health facility for medical care, hospitalization and long term management of ailment. These factors ordinarily affect attendance to work, keep casualties out of work and incapacitated and thus promotes lack of productivity, lose of income and financial dependency (Bloom, Cafiero, Jané-Llopis, AbrahamsGessel, Bloom, Fathima, Feigl, Gaziano, Mowafi,, Pandya, Prettner, Rosenberg, Seligman, Stein, \& Weinstein, 2011). Physical inactivity exerts heavy financial burden on medical care in both developed and developing counties of the world. It is a major cause of severe economic hardship to individuals, families, communities and the government (Department of Health of United Kingdom, 2013; Li, 2014).

Fuster and Kelly, (2010) while referring to the report of US Institute of Medicine observed that the macroeconomic burden of cardiovascular and chronic diseases in most developing countries of the world is much An estimated report on the economic burden of physical inactivity in advanced countries revealed that a total of $1.5-3.0 \%$ of the overall cost for medical care is associated with physical inactivity (Oldridge, 2008). In United States it was revealed that the amount of money spent on non-communicable diseases remains very high ranging from hundreds of billions to trillions of US dollars in one year alone. This estimate suggests that the current economic impact is indeed enormous. It was also projected that this level of financial burden will increase as the US population continues to grow. A global report has further shown that the cost of diseases associated with physical inactivity will rise to the tone of 30 trillion US dollars in 20 years to come. This estimate formed the $48 \%$ of the world GDP in 2010 and consequently brought millions of the world population to operate below poverty level (Bloom, Cafiero, Jané-Llopis, AbrahamsGessel, Bloom, Fathima, Feigl, Gaziano, Mowafi,, Pandya, Prettner, Rosenberg, Seligman, Stein, \& Weinstein, 2011). Besides the world wide lost in labour units due to mortality, mobility and cost of treating people with such ailments has resulted in reduction of the quantity and quality of labour force as well as human capital (Mayer-Foulkes, 2011).

\section{Implication for the Promotion of Healthy Lifestyle of Physical Activity}

A healthy lifestyle is that which enables an individual to maintain and improve health as well as well-being (WHO, 2005). It involves a way of living that helps an individual to enjoy good physical and emotional health (The Center for Reintegration, 2003). Healthy lifestyle for this paper could be conceived as the ability of an individual to embark on those activities that promotes sound health. Regular physical activity is an important component of a healthy lifestyle that promotes fitness and general well. While a life of inactivity has lots of negative health implications as discussed above being active is associated with very many benefits to health. Scientifically it has been proven that physical activity helps individuals to prevent and reduce their susceptibility to many NCDs as well as maintain physical and mental health. Physical activity improves general wellbeing, prolong life by at list five years, helps people keep in good shape, sleep well, enjoy leisure and carry out work and domestic chores without much stress. It also helps individuals to develop a sense of value, purpose, quality life, build sound relationships and good social living (Center for Spirituality \& Healing, 2013).

Despite these great benefits of physical activity lots of people rather prefer to be sedentary and this prevailing situation has resulted in an increase in diseases associated with inactivity such as CVDs, cancers, bone diseases, obesity and diabetes. In order to prevent and reduce the sever burdens of these health problems in the world there is need for a move from medical therapies to health promotion activities with focus on altering health risk behaviours that are modifiable. Such health risk behaviours among others include physical inactivity (Oldridge, 2008). Physical activity is required by both young and old and thus should be vigorously promoted as a lifestyle. It is recommended that children between 6-17 years of age should engage in physical activity for not less than 60 minutes per day. However, children less than five years who can walk without support are expected to be physically active for a minimum of three hours spread throughout a day. These recommendations are based on the numerous benefits of physical activity during childhood and adolescence. Regular physical activity during young age is known to help build strength, endurance, strong bones, and muscles. It also helps to improve blood pressure and blood cholesterol, regulate body weight, prevent anxiety and undue stress, develop positive self-esteem as well as enhances academic performance(U.S. Department of Health and Human Services, 2008; National Association for Sport and Physical Education, 2008; Department of Health, 2011).

Adults between 18-64 years on the other hand are expected to carry out moderate-intensity aerobic activity for at least two and half hours per week or vigorous-intensity aerobic

\section{Volume 4 Issue 12, December 2015}




\section{International Journal of Science and Research (IJSR) \\ ISSN (Online): 2319-7064}

Index Copernicus Value (2013): 6.14 | Impact Factor (2014): 5.611

activity for one hour and fifteen minutes per week. In addition this group is to do muscle-strengthening activities at least two days per week (Hittit, 2015). Adults above 64 years who finds it difficult to move freely are required to carry out physical activity for up to 3 or more days per week to improve balance and prevent falls. However older adults who cannot adhere to the recommendations for physical activity as a result of their health condition should remain physically active as far as their limitations permit (WHO, 2014). Children and adultsmust regularly meet up with these requirements in order to be physically fit. Children particularly should be made to carry out physical activity as a life's routine just as eating and sleeping (American Academy of Pediatrics, 2015). They should also be helped to develop the knowledge, skills, and confidence to be physically active for a lifetime. Promotion of physical activity should therefore be carried out in multiple sites. Places where physical activity could be promoted are the school, home, workplace and community

\section{School}

Promotion of physical activity in the school for pupils and staff is of utmost importance because these group of people spend much of their times in the school. Besides cultivating and maintaining a lifestyle of physical activity ideally starts from childhood and the school has much role to play in actualizing this (WHO, 2015a). The school has all it takes to ensure that young children obtain the required amount of daily physical activity according to WHO guidelines. Consequently, schools must efficiently provide and promote participation in physical activity programmes. These activities may include inter-school sports; classroom based physical activity, intramural physical activity clubs, and physical education. Schools should ensure that physical education is provided to all students in all grades and is taught by qualified teachers. Awareness programme on the importance of physical activity could also be organized regularly for staff and parents via the school PTA meeting (Center for Disease Control and Prevention, 2015,America Heart Association, 2015).

\section{Home}

Apart from the school, children should also be encouraged to remain active in their homes by engaging in domestic chores. In this regard parents and care givers have major promotive roles to play. Reducing the long hours children and adults spend watching television, using computer or internet at home as it is in modern times is important and should be replaced with home chores and a programme of organized exercise regimen(Austrialian Institute for Health and Welfare, 2015). Parents at home should endeavour to be exemplary since it has been observed that children whose parents are active are five times more likely to be active than those whose parents are not active(Health Service Executive, 2015)

\section{Workplace}

Workplace is another valuable site for the promotion of physical activity. Oyeyemi\& Adeyemi , (2013) observed that physical activity in the work places might help to prevent and control CVD among the working population. Education programme aimed increasing knowledge about physical activity could be carried out regularly in the workplace for members of staff. This programme may include individual or group counseling for those that have special need for physical activity(that is the obesed or overweight individuals). Materials containing information on physical activity could be distributed to members of staff through bulletins, boards, newsletters, classes, special locations such as cafeteria and conveniences. Social support programmes such as organizing sports teams and intraworkplace competitions are also needed to promote employees participation in physical activity(Centre for Disease Control and Prevention, 2013). Employers should assist in the promotion of physical activities in the workplace through providing enabling environment such as the provision of on the site physical activity facilities, showers and changing rooms. Mapping out time during work hours for workers to participate in physical activity is another promotive strategy that could be very useful in promoting physical activity in the workplace. Policies that encourage the use of stairs in the workplace, providing parks and encouraging staff to come to work by cycling or walking are all needed to achieve effective promotion of physical activity in the work place (Vinter, St. Laurent, Segal, 2008; WHO, 2008; U.S.Department of Health and Human Services, 2010).

\section{Community}

Promotion of physical activity is also needed at the community level. Community-wide campaign on physical activity using all aspect of the media such as the radio, television, and newspapers could be used for this purpose. Benefits and recommended programmes of physical activity in bill boards, posters and radio jingles could also be used to promote awareness of physical activity among the general population. Promoting a lifestyle of physical activity further involves the cooperation of the government and policy makers. There is need for the government to create enabling environment through polices and laws that are supportive. Government may therefore need to implement and enforce transportation regulations that will encourage people to walk and ride bicycles, create parks, play grounds and promote physical activity in schools and communities (Centers for Disease Control and Prevention, 2001; Kahn, Ramsey, Brownson, 2002).

\section{Conclusion}

The Health and economic burdens of physical inactivity to individuals, families, communities and the government are enormous. This lifestyle has become a public health menace and thus efforts should be made to reduce its deadly effect on health. This can be accomplished through vigorous and efficient promotion of healthy lifestyle of physical activity for both young and old

\section{Recommendations}

1) There is need for the government to create and implement urban and environmental regulations that will promote increased participation in physical activity among the general population.

2) Health educators should focus on awareness programmes for the promotion of physical activity

\section{Volume 4 Issue 12, December 2015}




\section{International Journal of Science and Research (IJSR) \\ ISSN (Online): 2319-7064}

Index Copernicus Value (2013): 6.14 | Impact Factor (2014): 5.611

3) Schools should be mandated by the government to teach physical education as a compulsory subject in primary, junior and senior secondary schools.

4) All aspects of the media should be used in propagation messages regarding physical activity

\section{References}

[1] American Heart Association (2015). Recommendation for physical activity in adults. Retrieved August 4, 2015 from www.heart.org/HEARTORG/Get

[2] Astralian Institute for Health Wealfare, (2015). Physical inactivity. Retrieved August 5 from http://www.aihw.gov.au/risk-factors-physical-inactivity/

[3] Austrialian Institute for Health and Welfare (2015). Physical inactivity. Retrieved August 5, 2015 from http://www.aihw.gov.au/risk-factors-physical-inactivity/

[4] Akarolo-Anthony, $\mathrm{S}$. $\mathrm{N}$. \&Adebamowohttp://www.biomedcentral.com/14712458/14/529/ - ins2, C. A 2014).Prevalence and correlates of leisure-time physical activity among Nigerians. BMC Public Health, 14 (529), doi:10.1186/1471-2458-14-529

[5] Bloom, D. E., Cafiero, E.T., Jané-Llopis, E., AbrahamsGessel, S., Bloom, L.R., Fathima, S., Feigl,A.B., Gaziano, T., Mowafi, M., Pandya, A., Prettner, K., Rosenberg, L., Seligman, B., Stein, A.Z., \& Weinstein, C. (2011). The Global Economic Burden of Noncommunicable Diseases. Geneva: World Economic Forum. Retrieved September 24, 2015 from www.weforum.org/EconomicsOfNCD

[6] Bumgardner, w. (2015). What is physical in activity? Retrieved August 5,2015 from http://walking.about.com/od/beginners/a/physicalinactivity.htm

[7] Centers for Disease Control and Prevention(2001). Increasing physical activity: a report on recommendations of the task force on community preventive services. MMWR Recommendation Report, 50 (RR-18), 1-14.

[8] Center for reintegration (2003).Healthy lifestyle. Retrieved September 28, 2015 from http://www.reintegration.com/resources/lifestyle/

[9] Center for Spirituality and Healing (2013). What is physical activity and fitness? Retrieved August 5 from http://www.takingcharge.csh.umn.edu/enhance-yourwellbeing/health/physical-activity- fitness/whatphysical-activity-fitness

[10] Centre for Disease Control and Prevention ( 2013). Promotion workplace health. Retrieved October 2, 2015 form

http://www.cdc.gov/workplacehealthpromotion/implem entation/topics/physical- activity.html

[11]Centers for Disease Control and prevention (2015).Physical activity facts. Retrieved September 7, 2015 from http://www.cdc.gov/healthyschools/physicalactivity/fact s.htm

[12] Cleere, M. (2015). Why are people becoming physically inactive these days? Retrieved Agust 5, 2015 fromvalid. physical-inactive

[13]Cole, P. (2012). Being inactive kills as many as cigarette. Retrieved August 4, 2015 from www.everydayhealth.com/longevity/0718/being-

inactive-kills-asmany-ascigarettes.aspx

[14] Dairy Council of California, (2015). Types of Physical Activity. Retrieved August 5 2015 from http://www.healthyeating.org/Healthy-Eating/HealthyLiving/Physical-Activity/Article-

Viewer/Article/238/types-of-physical-activity.aspx

[15] Department of Health (2011). Start Active, Stay Active: A report on physical activity for health from the four home countries' Chief Medical Officers. Retrieved 7/9/2015 from http://www.sustrans.org.uk/policyevidence/the-impact-of-our-work/related-academicresearch-and-statistics/physical-activity 7/9/2015

[16]Department of Health of United Kingdom(2013).Publications policy and guidance: at least five weeks: evidence on the impact of physical activity and its relationship to health. Retrieved November 30, 2013 http://webarchive.nationalarchives.gov.uk

[17]Depietro, M, (2011). 8 negative health effects of physical inactivity. Retrieved August 7, 2015 from http://www.symptomfind.com/health/effects-ofphysical-inactivity/

[18] Gallagher, J. (2015). Inactivity kkills more than obesity'. Retrieved August 7, 2015 from http://www.bbc.com/news/health-30812439

[19] Health- Manatū Hauora ( 2014). The dangers of inactivity and sedentary behaviour. Retrieved August 7, 2015 from http://www.health.govt.nz/yourhealth/healthy-living/food-and-physicalactivity/physical-activity/dangers-inactivity-andsedentary-behaviour

[20] Health Promotion Board, (2012). Types of physical activities. Retrieved August 5, 2012 from http://www.hpb.gov.sg/HOPPortal/health-article/4004

[21] Health Service Executive (2015). Physical activity. Retrieved Octobert 2, 2015 from https://www.healthpromotion.ie/health/physical_activity

[22] Hitti, M. (2015). Healthy Living: 8 Steps to Take Today. Retrieved August 30, 2015 from http://www.webmd.com/balance/features/healthyliving-8-steps-to-take-today

[23] I-Min, L., Shiroma, E., Lobelo,F., Puska, P., Bliar, S. N., \& Katzmarlyk, P. T. (2012). Effect of physical inactivity on major non-communicable diseases worldwide: an analysis of burden and life expectancy. The Lancet, 380 (9838), 219-229

[24] Kahn, E. B., Ramsey, L. T., Brownson, R. C.,(2002). The effectiveness of interventions to increase physical activity: a systematic review. American Journal of Preventive Medicine, 22(4 Suppl),73- 107.

[25] Levi, J., Vinter, S., St. Laurent, R., Segal, L. M. (2008). Fas in fat: how obesity policies are failing in America. Trust for America's Health

[26] Li, L.(2012). People can live longer by having more physical activity. Journal of Sport Health Science1, 7-8

[27] Merriam Webster Dictionary(2015). In-activity. Retrieved Agust 5, 2015 from http://www.merriamwebster.com/dictionary/inactive

[28] National Association for Sport and Physical Education(2008). Comprehensive school physical activity programmes. Reston, VA: National Association

\section{Volume 4 Issue 12, December 2015}




\section{International Journal of Science and Research (IJSR) \\ ISSN (Online): 2319-7064}

Index Copernicus Value (2013): 6.14 | Impact Factor (2014): 5.611

for Sport and Physical Education December 13, 2008 fromhttp://www.shapeamerica.org/cspap/resources.cfm

[29] National Heart, Lung and Blood Institute, (2011). What is physical activity? Retrieved August 5, 2015 from http://www.nhlbi.nih.gov/health/healthtopics/topics/phys/types

[30] NCHPAD (2015). Sedentary lifestyle is dangerous to your health. Retrieved August 7, 2015 from http://www.nchpad.org/403/2216/Sedentary Lifestyle $\sim$ i $\mathrm{s} \sim$ Dangerous $\sim$ to $\sim$ Your $\sim$ Health

[31] New Zealand Ministry of health (2015). Dangers of inactivity and sedentary lifestyle. Retrieved August 5, 2015 fromwww.health.govt.nz/your-health/healthyliving/food-and-phsycical-activity/ physicalactivity/dangers-inactivity-and-sendentary-behaviour

[32] NHS Health Scotland(2015). Introduction to physical activity. Retrieved August 5, 2015 http://ww w.healthscotland.com/Topics/HealthTopics/PhysicalAct ivity.aspx

[33] Oldridge, N. B. (2008).Economic burden of physical inactivity: healthcare costs associated with cardiovascular disease.European Journal of Cardiovascular Prevention Rehabilitation,15(2), 130139.doi:10.1097/HJR. 0b013e3282f19d42

[34] O'Riodan (2012). The neglected dimension: lancet series highlights global burden of physical inactivity.Retrieved August 5, 2015 from http://www.medscape.com/viewarticle/767648

[35] Oyeyemi A. L. \&Adeyemi, A (2013). Relationship of physical activity to cardiovascular risk factors in an urban population of Nigerian adults. Archives of Public Health, 71, 6

[36] South Australian Health (2012). The risk of inactivity. Retrieved August 7, 2015 from http://www.sahealth.sa.gov.au/wps/wcm/connect/public +content/sa+health+internet/healthy

[37] U.S. Department of Health and Human Services(2008). Physical Activity Guidelines Advisory Committee report. Retrieved September 29, 2015 from http://www.cdc.gov/healthyschools/physicalactivity/fact s.htm

[38] U.S.Department of Health and Human Services (2010). The surgeon general's vision for a healthy and fit nation. Rockville, MD: U.S. Department of Health and Human Services, Office of the Surgeon General

[39] WHO (2013). Health topics: physical activity. Retrieved November 30, 2013 from http://www.whoint/topics/physical-activityen/

[40] WHO( 2008). Preventing non-communicable diseases in the workplace through diet and physical activity. WHO/World Economic Report of a Joint Event

[41]WHO (2014). 10 facts on physical activity. RetriedAugust 5, 2015 from http://www.who.int/features/factfiles/physical acti vity/en/

[42] WHO( 2005). Preventing chronic diseases: a vital investment. WHO global report. Geneva

[43] WHO (2005). Participants at the 6th Global Conference on Health Promotion :The Bangkok Charter for health promotion in a globalized world. Geneva, Switzerland. Retrieved September 28, 2015 from https://simple.wikipedia.org/wiki/Healthy_lifestyle
[44] WHO(2015) Prevalence of insufficient physical Global Health Observatory data. Retrieved August 5, 2015 from activityhttp://www.who.int/gho/ncd/risk_factors/physic al_activity_text/en/

[45] $\overline{\mathrm{WHO}}(2015)$. Physical inactivity a leading cause of disease and disability. Retrieved August 5, 2015 from http://www.who.int/mediacentre/news/releases/release2 $3 / \mathrm{en} /$

[46] World Heart Federation (2015). Physical inactivity. Retrieved August 5, 2015 from http://www.world-heartfederation.org/cardiovascular-health/cardiovasculardisease-risk- factors/physical-inactivity/

[47]Zhang, J. \& Chaaban, J.( 2012). The economic cost of physical inactivity in China.Preventive Medicine, 56, 75-78 